\title{
Enhanced Ferroelectric and Converse Piezoelectric Properties of Dense Lead-Free $\mathrm{Na}_{0.4} \mathrm{~K}_{0.1} \mathrm{Bi}_{0.5} \mathrm{TiO}_{3}$ Ceramics for Actuator Applications
}

\author{
N. Shara Sowmya, Pravin Varade, Narayanan Venkataramani, Ajit R. Kulkarni* \\ Department of Metallurgical Engineering and Materials Science, Indian Institute of Technology Bombay, Mumbai, India \\ Email: *ajit.kulkarni@iitb.ac.in
}

How to cite this paper: Sowmya, N.S., Varade, P., Venkataramani, N. and Kulkarni, A.R. (2019) Enhanced Ferroelectric and Converse Piezoelectric Properties of Dense Lead-Free $\mathrm{Na}_{0.4} \mathrm{~K}_{0.1} \mathrm{Bi}_{0.5} \mathrm{TiO}_{3}$ Ceramics for Actuator Applications. Advances in Materials Physics and Chemistry, 9, 1-10.

https://doi.org/10.4236/ampc.2019.91001

Received: February 8, 2019

Accepted: March 9, 2019

Published: March 12, 2019

Copyright $\odot 2019$ by author(s) and Scientific Research Publishing Inc. This work is licensed under the Creative Commons Attribution International License (CC BY 4.0).

http://creativecommons.org/licenses/by/4.0/

(c) $\underset{\mathrm{EY}}{\mathrm{C}}$ Open Access

\begin{abstract}
In this work, lead-free $\mathrm{Na}_{0.4} \mathrm{Bi}_{0.5} \mathrm{TiO}_{3}-\mathrm{K}_{0.1} \mathrm{Bi}_{0.5} \mathrm{TiO}_{3}$ (NKBT) piezoelectric ceramics were prepared by the solid-state reaction method and their structural, ferroelectric and dielectric properties were systematically studied. NKBT sintered at $1150^{\circ} \mathrm{C}$ for $4 \mathrm{~h}$ exhibited highly dense $(96 \%-98 \%$ of the theoretical density) and uniform grains of size $1.1 \mu \mathrm{m}$. The coexistence of tetragonal $(\mathrm{P} 4 \mathrm{bm})$ and rhombohedral (R3c) phases due to the presence of morphotrophic phase boundary for the chosen composition has been confirmed by the Rietveld refinement studies. Enhanced ferroelectric properties such as remnant polarization $\left(\mathrm{P}_{\mathrm{r}}\right)$ and coercive field $\left(\mathrm{E}_{\mathrm{C}}\right)$ are found to be $37 \mu \mathrm{C} / \mathrm{cm}^{2}$ and $30 \mathrm{kV} / \mathrm{cm}$, respectively. The optimized synthesis procedure for NKBT ceramics resulted in enhanced strain (\%) and converse piezoelectric coefficient $\left(\mathrm{d}_{33}{ }^{*}\right)$ of $0.3 \%$ and $554 \mathrm{pm} / \mathrm{V}$ which is attributed to smaller grain size and switching of non $180^{\circ}$ domains. NKBT ceramics with such excellent piezoelectric properties can be considered as a promising candidate for actuator applications.
\end{abstract}

\section{Keywords}

Lead-Free Piezoelectric, Morphotropic Phase Boundary,

Converse Piezoelectric Coefficient, Actuator

\section{Introduction}

Piezoelectric crystals have multifunctional applications in the electronic industry for various devices such as sensors, transducers, actuators, resonators, filters, 
microphones etc. [1]. These devices work based on the fundamental piezoelectric properties, i.e., polarize electrically when subjected to a mechanical stress and conversely, induce mechanical deformation (change in the shape of crystal) under an applied electric field [2]. As of now, lead $(\mathrm{Pb})$ based systems are exhibiting high piezoelectric constants due to the presence of Morphotropic Phase Boundary (MPB), where the two phases co-exist. However, its toxicity to humans and environment, has motivated to look for lead-free piezoelectric systems. Besides the advantage of $\mathrm{MPB}$, a high Curie temperature $\left(\mathrm{T}_{\mathrm{C}}>250^{\circ} \mathrm{C}\right)$ is an essential factor for exhibiting stable piezoelectric characteristics over a wide temperature range [3].

Among such high temperature piezoelectric systems, $\mathrm{Na}_{0.5} \mathrm{Bi}_{0.5} \mathrm{TiO}_{3}$ (NBT) and $\mathrm{K}_{0.5} \mathrm{Na}_{0.5} \mathrm{NbO}_{3}(\mathrm{KNN})$ are believed to replace lead-based systems with high " $\mathrm{T}_{\mathrm{C}}$ " [4]. Smolenskii et al. [5] found NBT system with high piezoelectric properties compared to that of lead-based systems. Similar to PZT and PMN-PT, NBT [6] bismuth $\left(\mathrm{Bi}^{3+}\right)$ based compounds possess ion off centering driven by chemically active $6 \mathrm{~s}^{2}$ lone pair on $\mathrm{Bi}^{3+}$ ion, which is responsible for large structural distortions leading to greater polarizability. Nevertheless, due to the high coercive field $\left(\mathrm{E}_{\mathrm{C}}\right), \mathrm{NBT}$ requires very high field to change the domain orientation while poling which hinders the use of NBT in the conventional device [7].

The electrical and structural properties of NBT system can be modified by the substitution of larger $\mathrm{K}^{+}$ion in the Na-site which results in lattice distortion and can enable the formation of MPB with co-existence of rhombohedral and tetragonal phases [8]. In turn, the $\mathrm{K}^{+}$ion acts as a pinning site for long-range lattice diffusion thereby resulting in reduced grain size and increase in the domain mobility. This facilitates in achieving the low " $\mathrm{E}_{\mathrm{C}}$ " and enhanced ferro/piezo electric properties for NKBT ceramics [9]. A brief comparison of recently reported structural, ferroelectric and piezoelectric characteristics of both lead-based and lead-free [10] [11] [12] [13] [14] composites are given in Table 1. Compared to lead-based systems, the strain values are low in the case of lead-free systems due to their higher " $\mathrm{E}_{\mathrm{C}}$ " and hence require higher electric fields to induce the polarizability during the poling process. Hence, the objective of the present work is to enhance the strain and converse piezoelectric properties with reduced grain size by preparing dense $\mathrm{Na}_{0.4} \mathrm{~K}_{0.1} \mathrm{Bi}_{0.5} \mathrm{TiO}_{3}$ (NKBT) ceramics.

\section{Materials and Methods}

\subsection{Sample Preparation}

$\mathrm{Na}_{0.4} \mathrm{Bi}_{0.5} \mathrm{TiO}_{3}-\mathrm{K}_{0.1} \mathrm{Bi}_{0.5} \mathrm{TiO}_{3}$ solid solution was prepared by a conventional solid-state reaction method. High purity precursors ( $>99 \%$ from Sigma Aldrich, USA) used to prepare NKBT ceramics are Sodium carbonate $\left(\mathrm{Na}_{2} \mathrm{CO}_{3}\right)$, Potassium carbonate $\left(\mathrm{K}_{2} \mathrm{CO}_{3}\right)$, Bismuth oxide $\left(\mathrm{Bi}_{2} \mathrm{O}_{3}\right)$ and Titanium oxide $\left(\mathrm{TiO}_{2}\right)$. Stoichiometric amounts of carbonates and oxides were dried at $100^{\circ} \mathrm{C}$ for $4 \mathrm{~h}$ to remove any adsorbed moisture. Initially, the mixture of powders was ground in a mortar with acetone as a medium for $6 \mathrm{~h}$ for proper homogeneity and then 
Table 1. Recently reported structural, ferroelectric and piezoelectric properties of lead-based and lead-free systems.

\begin{tabular}{|c|c|c|c|c|c|c|c|}
\hline $\begin{array}{l}\text { Material } \\
\text { System }\end{array}$ & $\begin{array}{l}\text { Relative } \\
\text { Density }\end{array}$ & $\begin{array}{c}\mathrm{T}_{\mathrm{C}} \\
\left({ }^{\circ} \mathrm{C}\right)\end{array}$ & $\begin{array}{c}\operatorname{Pr} \\
\left(\mu \mathrm{C} / \mathrm{cm}^{2}\right)\end{array}$ & $\begin{array}{c}\mathrm{E}_{\mathrm{C}} \\
(\mathrm{kV} / \mathrm{cm})\end{array}$ & $\begin{array}{c}\mathrm{d}_{33}^{*} \\
(\mathrm{pm} / \mathrm{V})\end{array}$ & $\begin{array}{l}\text { Strain } \\
(\%)\end{array}$ & Ref. \\
\hline \multicolumn{8}{|l|}{ Lead-based } \\
\hline PLZT & $98.5 \%$ & 175 & 42.2 & 5.12 & - & 0.25 & [10] \\
\hline PMN-PT & - & 55 & 27 & 6.1 & - & - & [11] \\
\hline \multicolumn{8}{|l|}{$\underline{\text { Lead-free }}$} \\
\hline KNN & $95.10 \%$ & 410 & 11.4 & 8.5 & - & - & [12] \\
\hline LNN-BT & $97.55 \%$ & 275 & 11.2 & 19.2 & 174 & 0.12 & [13] \\
\hline NBT & $98.0 \%$ & 340 & 35 & 60 & 70 & 0.10 & [14] \\
\hline NKBT & $98.32 \%$ & 330 & 37 & 30 & 554 & 0.30 & * \\
\hline
\end{tabular}

PLZT: $\left(\mathrm{Pb}_{0.93} \mathrm{La}_{0.07}\right)\left(\mathrm{Zr}_{0.60} \mathrm{Ti}_{0.40}\right) \mathrm{O}_{3}$ PLZT (7/60/40). PMN-PT: $(1-x) \mathrm{Pb}\left(\mathrm{Mg}_{0.33} \mathrm{Nb}_{0.67}\right) \mathrm{O}_{3}-x \mathrm{PbTiO}_{3}(x=10)$ PMN-10PT. KNN: $\mathrm{K}_{0.5} \mathrm{Na}_{0.5} \mathrm{NbO}_{3}$. LNN-BT: $(100-x) \mathrm{Li}_{0.12} \mathrm{Na}_{0.88} \mathrm{NbO}_{3}-\mathrm{XBaTiO}_{3}(x=12.5)$ LNN-12.5BT. NBT: $\mathrm{Na}_{0.5} \mathrm{Bi}_{0.5} \mathrm{TiO}_{3}$. NKBT: $\mathrm{Na}_{0.4} \mathrm{~K}_{0.1} \mathrm{Bi}_{0.5} \mathrm{TiO}_{3}$.

solid state reacted at $800^{\circ} \mathrm{C}$ for $2 \mathrm{~h}$ to remove the volatile materials. The resultant powder was pulverized and X-ray powder diffraction (XRD) analyses were performed using a PANalytical X'PERT PRO MRD. To attain uniform particle size, calcined powders were ball milled in ethanol using Zirconia balls at $100 \mathrm{rpm}$ for 12 h. 1 wt\% Polyvinyl Alcohol (PVA) was added as a binder and uniaxially pressed into pellets (10 mm diameter with $1 \mathrm{~mm}$ thick) under a pressure of 145 MPa. Green pellets (density $\sim 62 \%-64 \%$ ) were sintered at $1150^{\circ} \mathrm{C}$ for $4 \mathrm{~h}$ at a slow heating rate of $3^{\circ} \mathrm{C} / \mathrm{min}$ in a high temperature programmable furnace. The measured volume shrinkage of the sintered NKBT pellets was around $30 \%$ $35 \%$. At $1150^{\circ} \mathrm{C}$, the bulk density of the NKBT ceramic was in the range of 5.75 $5.86 \mathrm{~g} / \mathrm{cm}^{3}$, which is $\sim 96 \%-98 \%$ of the theoretical density $\left(5.96 \mathrm{~g} / \mathrm{cm}^{3}\right)$, measured in accordance with Archimedes principle using water as the immersion fluid.

\subsection{Characterization}

The phase content and crystallinity of the sintered pellets are measured using PANalytical X'PERT PRO MRD with $\mathrm{Cu} \mathrm{K} \alpha(\lambda=1.5417 \AA)$ radiation at room temperature in the $2 \theta$ range from $20^{\circ}$ to $80^{\circ}$ with a step size of $0.0167^{\circ}$. The Rietveld analysis of the X-ray diffraction pattern was carried out for the MPB composition using FULLPROF software package. The microstructures of the polished samples are characterized using field emission scanning electron microscopy (FE-SEM) (JSM-7600). For proper grain boundary determination, the sintered NKBT pellets were thermally etched at $1100^{\circ} \mathrm{C}$ for $10 \mathrm{~min}\left(50^{\circ} \mathrm{C}\right.$ lower than the sintering temperature). The average grain size was determined using Image J software. In order to measure dielectric and ferroelectric measurements, samples were electroded using silver paste on both sides of the sintered NKBT pellets, dried and fired at $100^{\circ} \mathrm{C}$ for $2 \mathrm{~h}$. An Alpha-A high-resolution impedance analyzer (Novocontrol GmbH, Germany) was used for dielectric measurements. The 
electric field induced polarization (P-E) hysteresis loop, piezoelectric strain-electric field (S-E) curves and current-electric field (I-E) measurements were conducted using a standard FE loop tester (aixACCT TF Analyzer 2000) at $1 \mathrm{~Hz}$ connected with a miniature plane-mirror interferometer and the accessory laser interferometric vibrometer (SIOS-SP-S 120). For bipolar strain measurements, the maximum applied electric field was $5.5 \mathrm{MV} / \mathrm{m}$ at $1 \mathrm{~Hz}$.

\section{Results and Discussion}

Figure 1(a) shows the room temperature X-ray diffraction patterns of calcined $\left(800^{\circ} \mathrm{C} / 2 \mathrm{~h}\right)$ and sintered $\left(1150^{\circ} \mathrm{C} / 4 \mathrm{~h}\right) \mathrm{NKBT}$ ceramics. All the diffraction peaks exhibited pure perovskite structure without any secondary phases within the measured $2 \theta$ range of $20^{\circ}$ to $80^{\circ}$, indicating the formation of complete solid solution in the studied composition. A visual inspection of the peaks represented in Figure 1(b) imply that the splitting of $(111)_{\mathrm{R}}$ and $(200)_{\mathrm{T}}$ at $2 \theta$ angles around $40^{\circ}$ and $46^{\circ}$ indicates that K-substituted NKBT have co-existence of rhombohedral $(R)$ and tetragonal $(T)$ phases. The unit cell parameters of NKBT composition was determined by Rietveld refinement as shown in Figure 2. Since, the chosen composition is expected to have both the phases, the parameters of the $\mathrm{R} 3 \mathrm{c}$ space group with hexagonal lattice parameters [15] and tetragonal P4bm space group [16] were simultaneously used for Rietveld refining to obtain the minimum error in fitting of the lattice parameters. The obtained Rietveld refined values of NKBT are found to be consistent with the previously reported values [17]. The refined perovskite lattice parameters, discrepancy factor $\left(\mathrm{R}_{\mathrm{wp}}\right)$, expected values $\left(\mathrm{R}_{\mathrm{p}}\right)$ and percentage of both $\mathrm{R}$ - and T-phases along with goodness of fit index $\left(\chi^{2}\right)$ of NKBT are given in Table 2.

Figures 3(a)-(e) show the microstructure of as-sintered and thermally etched fractured surface of NKBT ceramics at different magnifications. A relatively high dense $(96 \%-98 \%)$ and uniform morphology was seen from the microstructure with uniform grain size distribution ranging from $1-1.2 \mu \mathrm{m}$. The measured

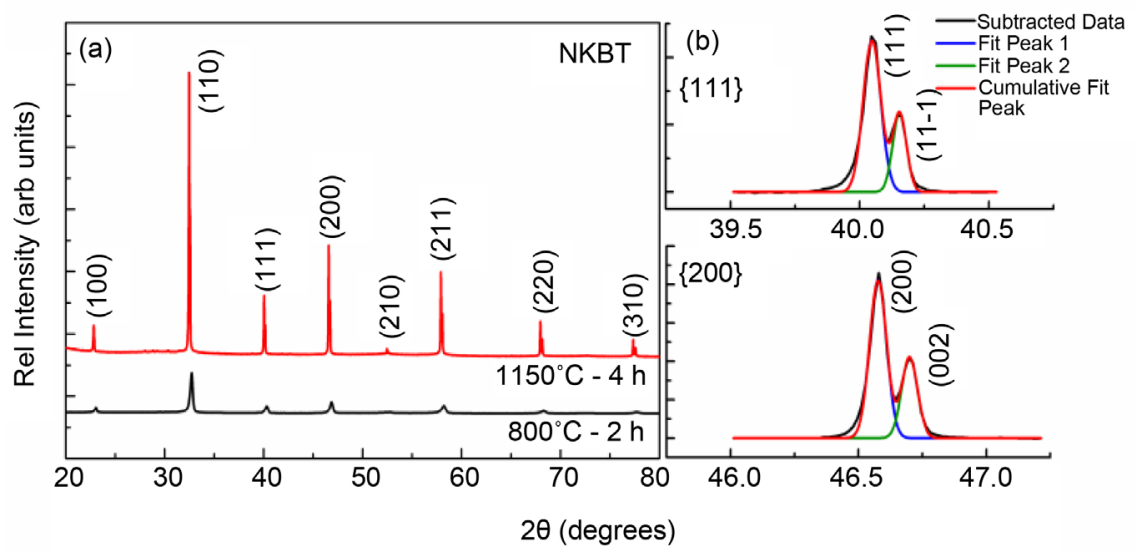

Figure 1. (a) X-ray diffraction patterns of calcined and sintered NKBT ceramics (b) enlarged view of (111) and (200) reflections representing fitted rhombohedral and tetragonal splitting. 


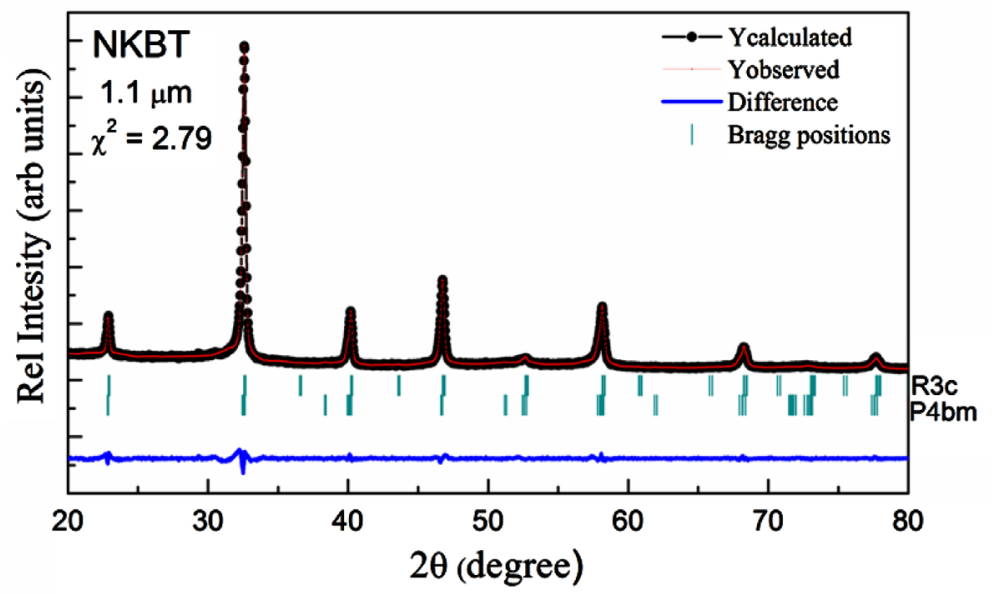

Figure 2. Rietveld fitted X-ray diffraction pattern of NKBT using R3c (hexagonal) and $\mathrm{P} 4 \mathrm{bm}$ (tetragonal) space group.

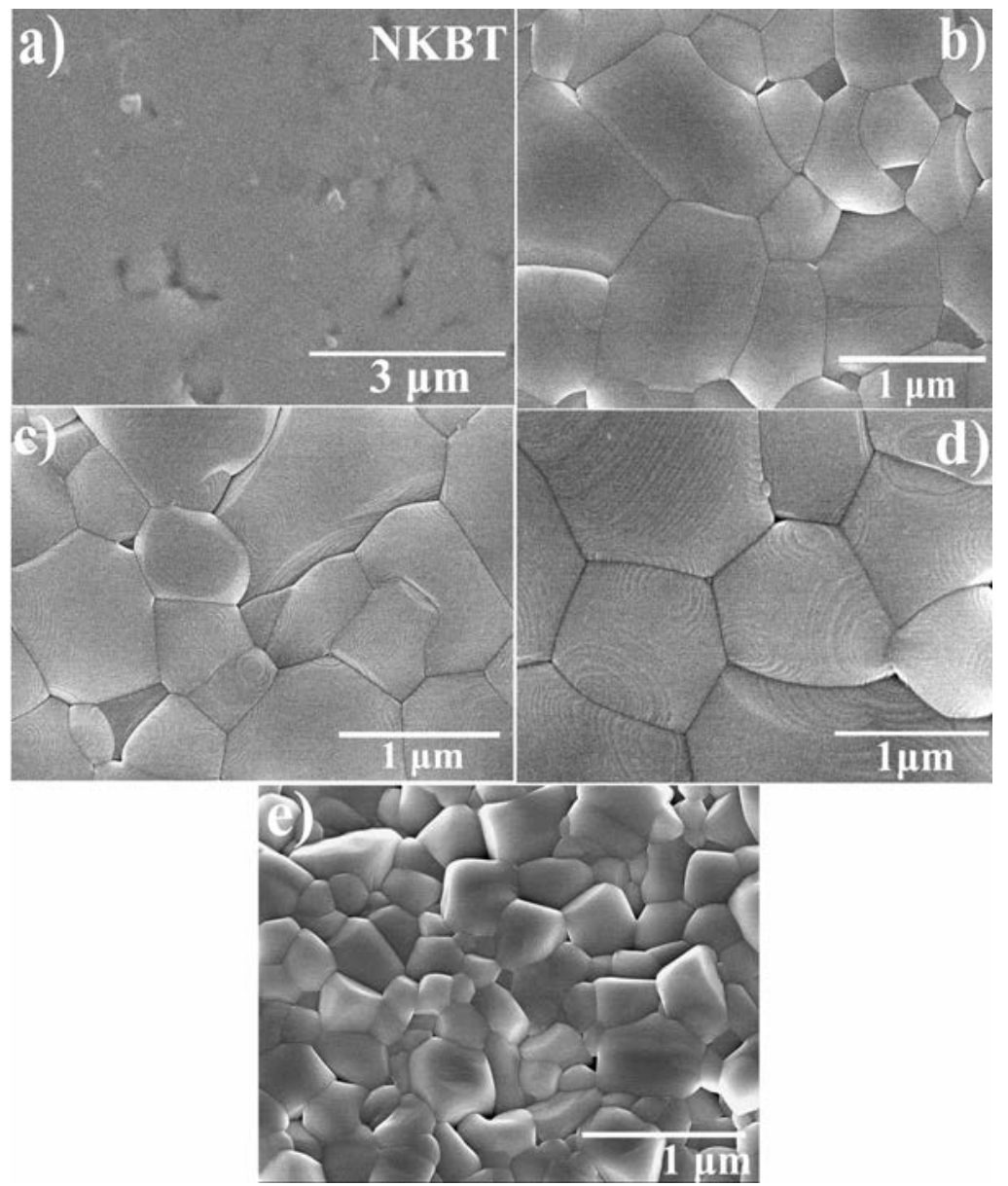

Figure 3. FESEM micrographs of (a) as-sintered, (b)-(d) thermally etched $\left(1100^{\circ} \mathrm{C}\right.$ for $\left.10 \mathrm{~min}\right)$ and (e) fractured surface of NKBT sintered at $1150^{\circ} \mathrm{C}$ for $4 \mathrm{~h}$.

grain size of NKBT is much smaller when compared to NBT $(7.8 \pm 3.2 \mu \mathrm{m})$ system [18]. Therefore, even a smaller substitution of $\mathrm{K}^{+}$in the NKBT solid solutions 
Table 2. Rietveld structural properties of NKBT ceramic sintered at $1150^{\circ} \mathrm{C}$ for $4 \mathrm{~h}$.

\begin{tabular}{ccc}
\hline Crystal system & Rhombohedral & Tetragonal \\
\hline Space group & $\mathrm{R} 3 \mathrm{c}$ & $\mathrm{P} 4 \mathrm{bm}$ \\
$\mathrm{a}, \mathrm{b}$ & 5.49700 & 5.49234 \\
$\mathrm{c}$ & 13.52987 & 3.87917 \\
$\alpha, \beta, \gamma$ & $90,90,120$ & $90,90,90$ \\
Volume $\%$ & 64.77 & 35.23 \\
\hline
\end{tabular}

$\chi^{2}=2.79, \mathrm{R}_{\mathrm{p}}=2.80$ and $\mathrm{R}_{\mathrm{wp}}=3.47$.

inhibits the grain growth. Absence of phase segregation at grain boundaries in the microstructure confirms the complete solubility of $\mathrm{K}^{+}$in the NBT lattice. From Figure 3(d), it is clearly observed that stripes pattern exist inside the each grain which are the characteristics of domain configuration in ferroelectric ceramics. G. Arlt et al. [19] ascribed that twinning occurs in all ferroelectric ceramics at a temperature below the structural phase transition in order to minimize the elastic energy. In turn, the fractured surface (Figure 3(e)) confirms the compact structure of fine grained NKBT ceramics with no traces of porosity leading to enhancement in ferroelectric and piezoelectric properties as discussed in the below sections.

Electric field dependent polarization (P-E) hysteresis loop and their corresponding switching current (I-E) of NKBT ceramics are shown in Figure 4(a). The observed well saturated loop depict typical ferroelectric behavior. In the present study, the measured " $\mathrm{E}_{\mathrm{C}}$ " value of $30 \mathrm{kV} / \mathrm{cm}$ which is lowest compared to the reported literature [20] [21] and " $\mathrm{P}_{\mathrm{r}}$ " value of $37 \mu \mathrm{C} / \mathrm{cm}^{2}$ is comparable to those prepared by conventional solid-state sintering method [18]. The reduced " $\mathrm{E}_{\mathrm{C}}$ " could be attributed to the smaller grain size due to the substitution of $\mathrm{K}^{+}$ which in turn reduces the domain width and enables the easy mobility of ferroelectric domains [22]. In addition, effective poling can be achieved since low electric field is sufficient to cause switching of domains. I-E hysteresis loop exhibits two typical current peaks at the threshold electric field of $+\mathrm{E}_{\mathrm{F}}$ and $-\mathrm{E}_{\mathrm{F}}$ at the $\mathrm{I}^{\mathrm{st}}$ and $\mathrm{III}^{\text {rd }}$ quadrant. These loading and unloading cyclic electric fields represent intrinsic ferroelectric character, indicating the domain switching behavior in NKBT ceramics.

Figure 4(b) represents bipolar strain curve of NKBT ceramics measured for a maximum electric field of $5.5 \mathrm{MV} / \mathrm{m}$ at $1 \mathrm{~Hz}$. The bi-polar strain curve exhibits symmetric "butterfly" curve with a maximum strain of $0.3 \%$. Moreover, in the present study, the negative strain $\left(S_{\text {neg }}\right)$ was absent when compared to reported literature [23] which is an additional feature of NKBT making more suitable for actuator applications. A high converse piezoelectric coefficient $\left(\mathrm{d}_{33}^{*}\right)$ of 554 $\mathrm{pm} / \mathrm{V}$ is calculated from the ratio of maximum unipolar strain to maximum electric field $\left(\mathrm{S}_{\text {unipolar }} / \mathrm{E}_{\text {max }}\right)$. Rao et al. has reported a maximum strain value of $0.12 \%$, where the grain size decreased and porosity will be increased upon K-substitution in NBT lattice [23]. A similar study was carried on electric field 

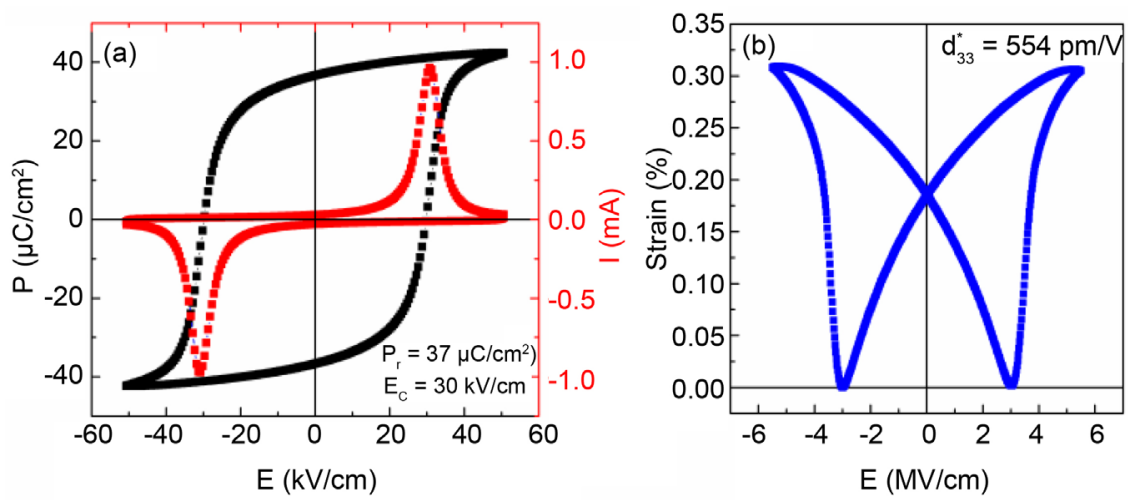

Figure 4. (a) and (b) shows polarization hysteresis loops, current (I) and corresponding piezoelectric response (strain) vs. electric field (E) properties of NKBT ceramics.

dependence of strain curves by Liu et al. [24] reports a maximum strain of $0.15 \%\left(\mathrm{~d}_{33}^{*}=250 \mathrm{pm} / \mathrm{V}\right)$ in NKBT system poled at $\mathrm{RT}(5 \mathrm{kV} / \mathrm{mm}$ for $15 \mathrm{~min})$. The large strain in the NKBT ceramics could possibly be attributed to: extrinsic contribution from movement and switching of non- $180^{\circ}$ domain walls driven by the external electric field in addition to pure piezoelectric response and intrinsic contribution due to change in the shape of the crystal lattice [25].

Temperature dependent dielectric constant at different frequencies of NKBT ceramic is shown in Figure 5. The temperature of maximum permittivity $\left(\mathcal{E}_{\max }\right.$, $\left.T_{\max }\right)$ values increases with increasing frequency. However, the opposite trend is noticed for the measured dielectric constant $\left(\varepsilon_{r}\right)$ values. The $\varepsilon_{r}$-T plot shows two broad dielectric peaks in the measured temperature range of $50^{\circ} \mathrm{C}-500^{\circ} \mathrm{C}$. The first hump between $90^{\circ} \mathrm{C}-120^{\circ} \mathrm{C}$ exhibits dielectric maxima at $\sim 100^{\circ} \mathrm{C}$, which represents relaxor behavior and corresponds to polymorphic phase transition (PPT) from R- to T-phases. The second broad peak signifies $\mathrm{T}$ to $\mathrm{C}$ (cubic) transition at $\sim 330^{\circ} \mathrm{C}$. The transition temperature $\left(\mathrm{T}_{\mathrm{C}}\right)$ was found to be increasing with increasing frequency. The possible reason for this kind of diffusive nature could be attributed to the weakening of long-range ferroelectric order, higher internal stresses and space charge effect [26] [27]. The measured values of " $\varepsilon_{r}$ " are comparable with the reported NKBT ceramics [18] [25].

\section{Conclusion}

The effect of reduced grain size on piezoelectric properties in K-substituted NBT system has been studied. A remarkable increase in strain (0.3\%) and reduced coercivity $\left(\mathrm{E}_{\mathrm{C}}=30 \mathrm{kV} / \mathrm{cm}\right)$ in $\mathrm{Na}_{0.4} \mathrm{Bi}_{0.5} \mathrm{TiO}_{3}-\mathrm{K}_{0.1} \mathrm{Bi}_{0.5} \mathrm{TiO}_{3}$ system could be attributed to highly dense and uniform microstructure. Interestingly, enhanced converse piezoelectric coefficient, $\mathrm{d}_{33}^{*}$ of $554 \mathrm{pm} / \mathrm{V}$, which is higher than the reported literature, could be a potential candidate for actuator applications. Further study includes optimizing the poling conditions (poling field, temperature and time) to enhance piezoelectric charge and voltage coefficients as it offers more understanding of domain switching mechanisms in NKBT. For an actuator, in addition to piezoelectric properties, precise mechanical control is also 


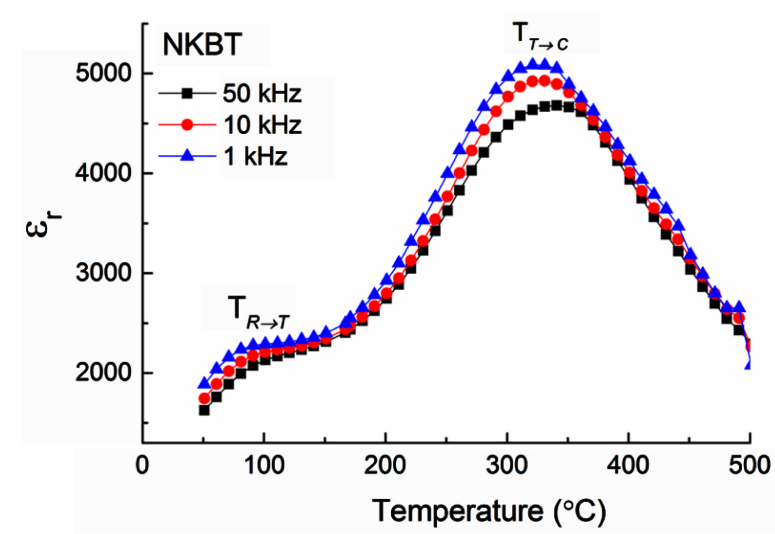

Figure 5. Temperature dependent dielectric constant $\left(\varepsilon_{\mathrm{r}}\right)$ of NKBT measured at different frequencies.

equally important for device fabrication and the above studies are currently underway.

\section{Acknowledgements}

The authors gratefully acknowledge the SAIF and IRCC IIT Bombay for providing FE-SEM and Broadband dielectric spectrometer facilities.

\section{Conflicts of Interest}

The authors declare no conflicts of interest regarding the publication of this paper.

\section{References}

[1] Jaffe, B., Cook Jr., W.R. and Jaffe, H. (1971) Piezoelectric Ceramics. Academic Press, New York.

[2] Rodel, J., Webber, K.G., Dittmer, R. and Jo, W. (2015) Transferring Lead-Free Piezoelectric Ceramics into Applications. Journal of the European Ceramic Society, 35, 1659-1681. https://doi.org/10.1016/j.jeurceramsoc.2014.12.013

[3] Saito, Y., Takao, H., Tani, T., Nonovama, T., Takatori, K., Homma, T., Nagaya, T. and Nakamura, M. (2004) Lead-Free Piezoelectrics. Nature, 432, 84-87. https://doi.org/10.1038/nature03028

[4] Cohen, R.E. (2000) Theory of Ferroelectrics: A Vision for the Next Decade and Beyond. Journal of Physics and Chemistry of Solids, 61, 139-146. https://doi.org/10.1016/S0022-3697(99)00272-3

[5] Smolenskii, G.A. and Agranovskaya, A.I. (1960) Dielectric Polarization of a Number of Complex Compounds. Soviet Physics, Solid State, 1, 1429-1437.

[6] Hill, N.A. and Rabe, K.M. (1999) First-Principles Investigation of Ferromagnetism and Ferroelectricity in Bismuth Manganite. Physical Review B, 59, Article ID: 8759. https://doi.org/10.1103/PhysRevB.59.8759

[7] Wang, X.X., Kwok, K.W., Tang, X.G., et al. (2004) Electromechanical Properties and Dielectric Behavior of $\left(\mathrm{Na}_{1 / 2} \mathrm{Bi}_{1 / 2}\right)_{(1-1.5 x)} \mathrm{Bi}_{x} \mathrm{TiO}_{3}$ Lead-Free Piezoelectric Ceramics. Solid State Communications, 129, 319-323.

https://doi.org/10.1016/j.ssc.2003.10.017 
[8] Karthik, T. and Saket, A. (2017) Enhanced Mechanical and Ferroelectric Properties through Grain Size Refinement in Site Specific Substituted Lead-Free $\mathrm{Na}_{(0.5-x)}$ $\mathrm{K}_{\mathrm{x}} \mathrm{Bi}_{0.5} \mathrm{TiO}_{3}(x=0-0.1)$ Ceramics. Materials Letters, 146, 81-83.

[9] Chen, I.-W. (1993) Mobility Control of Ceramic Grain Boundaries and Interfaces. Materials Science and Engineering: A, 166, 51-28. https://doi.org/10.1016/0921-5093(93)90309-3

[10] Liu, Y.F., Ling, Z.Y. and Zhuo, Z.P. (2017) High Piezoelectricity of PLZT Ceramics with Strong Frequency-Dielectric Dispersion below Depolarization Temperature. Journal of Alloys and Compounds, 727, 925-930. https://doi.org/10.1016/j.jallcom.2017.08.113

[11] Zhang, T.F., et al. (2016) Energy-Storage Properties and High-Temperature Dielectric Relaxation Behaviors of Relaxor Ferroelectric $\mathrm{Pb}\left(\mathrm{Mg}_{1 / 3} \mathrm{Nb}_{2 / 3}\right) \mathrm{O}_{3}-\mathrm{PbTiO}_{3} \mathrm{Ce}-$ ramics. Journal of Physics D: Applied Physics, 49, Article ID: 095302.

[12] Vendrell, X., et al. (2015) Improving the Functional Properties of $\left(\mathrm{K}_{0.5} \mathrm{Na}_{0.5}\right) \mathrm{NbO}_{3}$ Piezoceramics by Acceptor Doping. Journal of the European Ceramic Society, 35, 125-130. https://doi.org/10.1016/j.jeurceramsoc.2014.08.033

[13] Mitra, S. and Ajit, R.K. (2016) Synthesis and Electrical Properties of New Lead-Free $(100-x) \mathrm{Li}_{0.12} \mathrm{Na}_{0.88} \mathrm{NbO}_{3}-x \mathrm{BaTiO}_{3}(0 \leq x \leq 40)$ Piezoelectric Ceramics. Journal of the American Ceramic Society, 99, 888-895. https://doi.org/10.1111/jace.14016

[14] Aksel, E., Forrester, J.S., Foronda, H.M., Dittmer, R., Damjanovic, D. and Jones, J.L. (2012) Structure and Properties of La-Modified $\mathrm{Na}_{0.5} \mathrm{Bi}_{0.5} \mathrm{TiO}_{3}$ at Ambient and Elevated Temperatures. Journal of Applied Physics, 112, Article ID: 05411. https://doi.org/10.1063/1.4751357

[15] Jones, G.O. and Thomas, P.A. (2002) Investigation of the Structure and Phase Transitions in the Novel A-Site Substituted Distorted Perovskite Compound $\mathrm{Na}_{0.5} \mathrm{Bi}_{0.5} \mathrm{TiO}_{3}$. Acta Crystallographica Section B, B58, 168-178. https://doi.org/10.1107/S0108768101020845

[16] Jones, G.O., Kreisel, J. and Thomas, P.A. (2002) A Structural Study of the $\left(\mathrm{Na}_{1-x} \mathrm{~K}_{x}\right)_{0.5} \mathrm{Bi}_{0.5} \mathrm{TiO}_{3}$ Perovskite Series as a Function of Substitution $(x)$ and Temperature. Powder Diffraction, 17, 301-319. https://doi.org/10.1154/1.1505047

[17] Veera Gajendra Babu, M., Bagyalakshmi, B., Venkidu, L. and Sundarakannan, B. (2017) Grain Size Effect on Structure and Electrical Properties of Lead-Free $\mathrm{Na}_{0.4} \mathrm{~K}_{0.1} \mathrm{Bi}_{0.5} \mathrm{TiO}_{3}$ Ceramics. Ceramics International, 43, 12599-12604. https://doi.org/10.1016/j.ceramint.2017.06.137

[18] Otonicar, M., Skapin, S.D., Spreitzer, M. and Suvorov, D. (2010) Compositional Range and Electrical Properties of the Morphotropic Phase Boundary in the $\mathrm{Na}_{0.5} \mathrm{Bi}_{0.5} \mathrm{TiO}_{3}-\mathrm{K}_{0.5} \mathrm{Bi}_{0.5} \mathrm{TiO}_{3}$ System. Journal of the European Ceramic Society, 30, 971-979. https://doi.org/10.1016/j.jeurceramsoc.2009.10.006

[19] Arlt, G. (1990) Twinning in Ferroelectric and Ferroelastic Ceramics: Stress Relief. Journal of Materials Science, 25, 2655-2666. https://doi.org/10.1007/BF00584864

[20] Veera Gajendra Babu, M., Bagyalakshmi, B., Pathinettam Pandiyan, D., Ren, Y. and Sundarakannan, B. (2017) Grain Size Induced Monoclinic (Cm) to Rhombohedral (R3c) Transformation in Sodium Potassium Bismuth Titanate Ceramics. Scripta Materialia, 141, 67-71. https://doi.org/10.1016/j.scriptamat.2017.07.022

[21] Veera Ganjendra Babu, M., Abdul Kader, S.M., Muneeswaran, M., Giridharan, N.V., Pathinettam Padiyan, D. and Sundarakannan, B. (2015) Enhanced Piezoelectric Constant and Remnant Polarization in K-Compensated Sodium Potassium Bismuth Titanate. Materials Letters, 146, 81-83.

https://doi.org/10.1016/j.matlet.2015.01.152 
[22] Zheng, P., Zhang, J.L., Tan, Y.Q. and Wang, C.L. (2012) Grain-Size Effects on Dielectric and Piezoelectric Properties of Poled $\mathrm{BaTiO}_{3}$ Ceramics. Acta Materialia, 60, 5022-5030. https://doi.org/10.1016/j.actamat.2012.06.015

[23] Narayana Rao, B., Senyshyn, A., Olivi, L., Vasant, S. and Ranjan, R. (2016) Maintaining Local Displacive Disorders in $\mathrm{Na}_{0.5} \mathrm{Bi}_{0.5} \mathrm{TiO}_{3}$ Piezoelectrics by $\mathrm{K}_{0.5} \mathrm{Bi}_{0.5} \mathrm{TiO}_{3}$. Journal of the European Ceramic Society, 36, 1961-1972.

[24] Liu, X., Zhai, J., Shen, B., Li, F., Zhang, Y., Li, P. and Liu, B. (2017) Electric-Field-Temperature Phase Diagram and Electromechanical Properties in Lead-Free $\left(\mathrm{Na}_{0.5} \mathrm{Bi}_{0.5}\right) \mathrm{TiO}_{3}$. Journal of the European Ceramic Society, 37, 1437-1447. https://doi.org/10.1016/j.jeurceramsoc.2016.12.020

[25] Li, F., Jin, L., Xu, Z. and Zhang, S. (2014) Electrostrictive Effect in Ferroelectrics: An Alternative Approach to Improve Piezoelectricity. Applied Physics Reviews, 1, Article ID: 011103. https://doi.org/10.1063/1.4861260

[26] Okazaki, K. and Nagato, K. (1973) Effects of Grain Size and Porosity on Electrical and Optical Properties of PLZT Ceramics. Journal of the American Ceramic Society, 56, 82. https://doi.org/10.1111/j.1151-2916.1973.tb12363.x

[27] Uchino, K. and Nomura, S. (1982) Critical Exponents of the Dielectric Constants in Diffused-Phase-Transition Crystals. Ferroelectrics Letters, 44, 55-61.

https://doi.org/10.1080/07315178208201875 